\title{
Natural organochlorines as precursors of 3-monochloropropanediol esters in vegetable oils
}

\begin{abstract}
During high-temperature refining of vegetable oils, 3-monochloropropanediol (3-MCPD) esters, possible carcinogens, are formed from acylglycerol in the presence of a chlorine source. To investigate organochlorine compounds in vegetable oils as possible precursors for 3-MCPD esters, we tested crude palm, soybean, rapeseed, sunflower, corn, coconut, and olive oils for the presence of organochlorine compounds. Having found them in all vegetable oils tested, we focused subsequent study on oil palm products. Analysis of the chlorine isotope mass pattern exhibited in high-resolution mass spectrometry enabled organochlorine compound identification in crude palm oils as constituents of wax esters, fatty acid, diacylglycerols, and sphingolipids, which are produced endogenously in oil palm mesocarp throughout ripening. Analysis of thermal decomposition and changes during refining suggested that these naturally present organochlorine compounds in palm oils and perhaps in other vegetable oils are precursors of 3-MCPD esters. Enrichment and dose-response showed a linear relationship to 3-MCPD ester formation and indicated that the sphingolipid-based organochlorine compounds are the most active precursors of 3-MCPD esters
\end{abstract}

Keyword: 3-MCPD esters; Wax ester; Fatty acid; Diacylglycerol; Sphingolipid; Palm oil; chlorine Isotopic mass patterns; High-resolution mass spectrometry 